\title{
HISTOPATHOLOGY ASPECTS AND FIBROSIS EVALUATION OF BOVINE NATURALLY INFECTED LIVERS BY Fasciola hepatica
}

\author{
Leonardo Oliveira Trivilin', Dyeime Ribeiro de Sousa', Louisiane de Carvalho \\ Nunes ${ }^{1}$, Noeme de Sousa Rocha ${ }^{2}$, Isabella Vilhena Freire Martins ${ }^{1}$ \\ 1 UFES \\ 2 UNESP \\ Correspondência: Dyeime Ribeiro de Sousa: dyeimester@gmail.com
}

\begin{abstract}
Fasciolosis is a zoonotic disease that infects especially ruminants and the liver damages in chronic infection caused by the parasite are very severe. The aim of this study was to evaluate the histopathological findings in liver of cattle naturally infected with Fasciola hepatica, as well as propose a classification of liver damage caused by this disease based on the chronic inflammation and fibrosis. Were used fragments of the right lobe and left of one hundred livers the cattle. Those fragments were subjected to histological processing and staining with haematoxylineosin and Masson's trichrome. Assigned to graduate I to III for the classification of lesions according to the intensity of the inflammatory and fibrotic changes. The lesions more prevalent were biliary duct proliferation, mononuclear cell infiltration, arteriosclerosis, and periportal and periductal fibrosis. Fibrotic lesions were more intense than the inflammatory and $\mathbf{4 5 \%}$ of the samples belonged to category II, followed by $39 \%$ in category I and $16 \%$ in category III. The proposed categorization of pathological liver injury in chronic fasciolosis in naturally infected cattle proved is a valuable method of microscopic evaluation, since it allows determining the evolution of this disease.
\end{abstract}

Key Words: cattle, Fasciola hepatica, fascioliasis, liver

\section{ASPECTOS HISTOPATOLÓGICOS E AVALIAC̄̃̃O DE FIBROSE EM FÍGADOS BOVINOS NATURALMENTE INFECTADOS POR FASCIOLA HEPATICA}

RESUMO: Fasciolose é uma zoonose que infecta especialmente os ruminantes e os danos ao fígado causado pela infecção crônica pelo parasito são graves. Objetivou-se com este estudo avaliar os achados histopatológicos no fígado de bovinos naturalmente infectados com Fasciola hepatica, bem como propor a classificação de lesão hepática causada por essa doença baseado na inflamação crônica e fibrose. Foram utilizados fragmentos do lobo direito e esquerdo de 100 fígados bovinos com fasciolose. Os fragmentos foram submetidos a processamento histológico e coloração com hematoxilina e eosina (HE) e Tricrômico de Masson. Atribuiu-se a graduação de I a III para a classificação das lesões, de acordo com a intensidade das alterações inflamatórias e fibróticas. As lesões mais prevalentes foram a proliferação do ducto biliar, infiltração de células mononucleares, arteriosclerose e fibrose periportal e periductal. Lesões fibróticas foram mais intensas que as inflamatórias e $\mathbf{4 5} \%$ das amostras foram classificadas na categoria II, seguido de $39 \%$ na categoria I e $16 \%$ na categoria III. A proposta de categorização histopatológica da lesão hepática em fasciolose crônica em bovinos naturalmente infectados é um método valioso de avaliação microscópica, uma vez que permite determinar a evolução da doença.

Palavras-chave: bovinos, Fasciola hepatica, fasciolose, fígado 


\section{INTRODUCTION}

Fasciolosis is a zoonotic disease caused by a digenetic trematode which could infest different animal species, especially ruminants (Who, 1995).

The liver damage in chronic infection are very severe. Macroscopically, the injuries generate discard of the liver and considerable economic losses. Microscopically, the damage is considerable and undermine integrity of liver function, and commonly include injuries in biliary ducts, calcification, fibrosis and inflammatory infiltration (Bostelmann et al., 2000; Marcos et al., 2007; Kishida et al., 2013). To evaluate an affected bovine liver and to establish a histopathological classification of injury would facilitate the understanding of pathogenesis and the level of involvement (Riet-Correa et al. 2001).

To Boray (1969), factors related to the parasite and the host and environmental factors influence the pathogenesis and symptoms caused by infection. However, there are few morphological liver data in animals with natural infection, as well as absence of data on the anatomical distribution of lesions caused by the parasite. Furthermore, no literature indicated a specific report classifying the hepatic injuries in chronic fasciolosis by taking into account both inflammatory and fibrotic lesions in natural infection.

Most articles in the literature mentions the relations of parasitic loads and degrees of injury in experimental infections, which is not always consistent with reality. The pathological classification based on analysis of liver lesions caused by parasites in no experimental infection will help to improve the diagnosis of fasciolosis, since it allows to establish the degree of damage caused by the parasite. In addition, it would promote new methods of diagnosis in accordance with standard techniques, or even the development of new drugs able to reverse the damage already established, since the biopsy technique can be used.

Therefore, this study aimed at evaluating the histopathological finds and hepatic fibrosis in liver of bovine naturally infected by Fasciola hepatica, as well proposal of a classification of bovine hepatic lesions caused by chronic fasciolosis.

\section{MATERIAL AND METHODS}

\section{Samples and Histopathology evaluation}

One hundred bovine livers with fasciolosis in the slaughterhouse of Atílio Vivacqua, Espírito Santo, Brazil, were used. The animals had various ages, both sexes and varied diet, with approximate weight of $450 \mathrm{~kg}$, and all animals were from Southern Espírito Santo and sacrificed under the inspection of the Instituto de Defesa Agropecuária e Florestal do Espírito Santo (IDAF-ES, Brazil), and the livers were macroscopically searched for the presence of Fasciola hepatica. The cattle were slaughtered between March and July 2008.

Fragments of each hepatic lobe, right and left, of each liver was sampled. These fragments were collected with about $6 \mathrm{~cm}^{2}$ of visceral surface, using the rectangular shape to the right lobe and triangular shape to the left lobe. The samples were packed in bottles that contained $10 \%$ formalin $(9: 1)$ properly identified to be taken for histopathological evaluation, stained in haematoxylin-eosin (HE) and Masson's trichrome for the evaluation of morphological alterations, considering different levels of inflammatory variants and fibrotic lesions: biliary ducts proliferation in the portal space, inflammatory infiltration, the presence of 
eosinophyles, vascular sclerosis, area of necrosis, acinar formation, hepatic degeneration and atrophy, portal space fibrosis and diffuse fibrosis. The samples were also evaluated as to the presence or absence of the alterations above mentioned, and its intensity (discrete + , moderate ++ , severe +++ ).

Furthermore, were evaluated atherosclerosis along the connective tissue deposition in veins and sinusoids. For the periportal and periductal fibrosis were used evaluation parameters based on the number of layers of connective tissue, namely the absence of fibrosis, fibrosis of layers 1-2, layers 3-5 and $>6$ layers of fibrosis. For the distribution of fibrosis, were used the classification cited by Marcos et al. (2007) in that fibrosis in the liver parenchyma is seen in three stages: stage I - fibrosis in the portal space with few focal areas around lesions sometimes caused by the parasite, stage II - fibrosis observed throughout the liver parenchyma with long septa separated from each other; stage III - long and prominent fibrosis septa widely distributed throughout the parenchyma with regenerative nodules.

Because a significant injury to fibrosis in cattle infected with Fasciola hepatica, the histopathological findings for this lesion in space door and periductal region as well as its distribution by the liver parenchyma underwent comparison between the right and left lobes.

\section{Proposal Classification of chronic lesions}

A classification system was proposed to standardize the description of the lesions. An attempt to compare the pathological changes with chronic infection was carried. Liver damage were splited in three categories, ranging from degree I to III, based in magnitude and severity of inflammatory and fibrotic changes. The degree I presented prevailed discrete injuries; the degree II showed moderate injuries, the degree III presented severe injuries as displayed in the table below (Table 1). Samples that fell into more than one category, the fibrotic lesions were considered the most important changes to the definition of the classification.

\begin{tabular}{|c|c|c|}
\hline $\begin{array}{l}\text { Chronic } \\
\text { classification }\end{array}$ & injury & Morphological findings \\
\hline Degree I & & $\begin{array}{l}\text { Periportal fibrosis (absent or until } 5 \text { layers) } \\
\text { Absent to small quantity diffuse fibrosis } \\
\text { Biliary ducts' hyperplasia in portal space (absent or } \\
\text { from } 2 \text { to } 3 \text { layers) } \\
\text { Mononuclear inflammatory infiltration absent or } \\
\text { discrete (associated or not to eosinophyles) } \\
\text { Absenœ or presence of arteriosclerosis }\end{array}$ \\
\hline Degree II & & $\begin{array}{l}\text { Periportal fibrosis (until } 6 \text { layers) } \\
\text { Periductal fibrosis (if present/until } 6 \text { layers) } \\
\text { Diffuse fibrosis discrete to moderate } \\
\text { Biliary ducts' hyperplasia in portal space (until } 4 \\
\text { layers) } \\
\text { Discrete to moderate mononuclear inflammatory } \\
\text { infiltration diffuse associated to eosinophyles } \\
\text { Presence of arteriosclerosis }\end{array}$ \\
\hline Degree III & & $\begin{array}{l}\text { Periportal fibrosis ( }>6 \text { layers) } \\
\text { Periductal fibrosis (if present }>66 \text { layers) } \\
\text { Diffuse fibrosis moderate to severe } \\
\text { Biliary ducts' hyperplasia in portal space ( }>4 \text { layers) } \\
\text { Severe monoruclear inflammatory infiltration diffuse } \\
\text { Acinar formation in main ducts (when present) } \\
\text { Hepatic atrophy and/or degeneration (Present or } \\
\text { ausence) } \\
\text { Presence of arteriosclerosis }\end{array}$ \\
\hline
\end{tabular}

\section{Statistical analysis}

The statistical analysis included a descriptive analysis of histopathological findings. Data were arranged in table and to make sure values to the scores found, where 0 = absent, 1 for mild, 2 for moderate, and 3 for severe. In the case of bile duct proliferation, scores were: 0 for absent, 1 for proliferation from 2 to 3 ducts, and 3 for proliferation of more than four ducts. For comparison between the fibrotic liver lobes was used nonparametric test for two independent samples Mann-Whitney test ( $\alpha=5 \%$ ).

For the evaluation of variables found in histopathology between and within each category of proposed chronic injury, were used the mean scores and application of non-parametric test of Kruskal Wallis $(\alpha=5 \%)$ followed by Dunn's Test $(\alpha=5 \%)$. Spearman correlation was used to study the relationship between inflammation and ductal proliferation. 


\section{RESULTS}

\section{Histopathology evaluation}

A summary of the major histopathological changes are shown in table 2. As to inflammatory infiltration, it was observed the presence of mononuclear infiltration. The foci of inflammatory infiltration periportal and perivascular (centrilobular veins) were observed mainly, however, in some samples, especially those considered degree III, the distribution of inflammation extended throughout much of the parenchyma.

Table 2-Porcentage of histopathological findings of 100 bovine natural infected livers by Fasciola hepatica.

\begin{tabular}{lcccc}
\hline & PRESENCE & DISCRETE & MODERATE & SEVERE \\
\hline Biliary duct proliferation & $89 \%$ & - & - & - \\
Inflammatory infiltration & $95 \%$ & $50,53 \%$ & $32,63 \%$ & $16,84 \%$ \\
Eosinophiles infilitration & $85 \%$ & $61,18 \%$ & $21,18 \%$ & $17,64 \%$ \\
Necrosis area & $4 \%$ & - & - & - \\
Acinar formation & $18 \%$ & - & - & - \\
Hepatic atrophy & $8 \%$ & - & - & - \\
Arteriosclerosis & $96 \%$ & $42 \%$ & $44 \%$ & $10 \%$ \\
Periportal fibrosis & $100 \%$ & $23 \%$ & $61 \%$ & $16 \%$ \\
Periductal fibrosis ${ }^{*}$ & - & $10 \%$ & $29 \%$ & $14 \%$ \\
\hline${ }^{*}$ evaluated when the ducts presented their calbre ranging from intermediate to great
\end{tabular}

Periportal fibrosis was present in all of evaluated samples, in both lobes. Periductal fibrosis was evaluated when the ducts presented their calibre ranging from intermediate to great. No duct of great calibre was found in $47 \%$ evaluated samples. The distribution of fibrosis in the hepatic parenchyma was also evaluated. Eight percent of the samples showed absence of fibrosis in the parenchyma. Stage I of fibrosis was noticed in $46 \%$, stage $/ /$ in $37 \%$ and stage III of fibrosis in $\mathbf{9 \%}$.

The comparison between the periportal fibrosis right and left lobes showed no difference in collagen deposition in the space port of these two lobes. However, the left lobe was more predisposing for collagen deposition around the bile ducts (periductal fibrosis) significant difference in relation to the right lobe $(P<\mathbf{0 , 0 0 0 1})$. Regarding the distribution of fibrosis by liver parenchyma was no difference between right and left hepatic lobes, occurring in the latter greater distribution of fibrosis $(P=0,0025)$.

\section{Classification of chronic lesions}

The results of the histopathological analysis of the livers chronically affected by Fasciola hepatica. In natural infection revealed that $45 \%$ of the samples presented lesions into the category II, followed by $39 \%$ in category $\mathrm{I}$, and $16 \%$ into category I. The histological sections of different classifications are demonstrated in Figure 1.

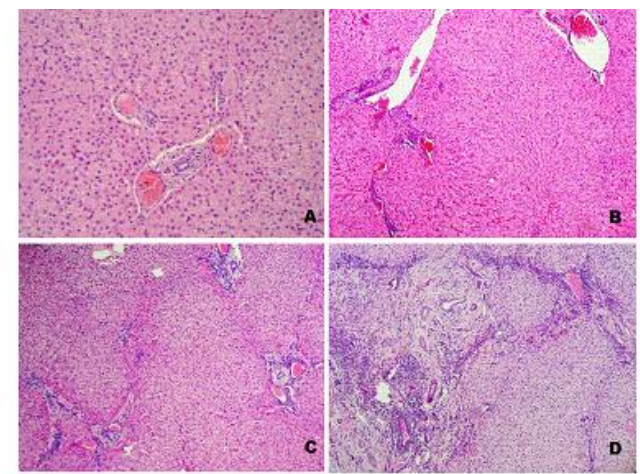

Figure 1- Histologic bovine liver sections. (A) Normal Iver. (B) Chronic infected live by Fasciola hepatica, degree I. (C) Chronic infected liver by Fasciola
hepatica, degree II. (D) Chronic infeded liver by Fasciola hepatica, degree III. (HE stain, X200).

After histological classification, a study using the principal finds, with the exception of fibrotic lesions, was conducted to evaluate their behaviour into each category and between categories.

In relation to biliary duct proliferation, there was no significant difference between categories II and III. The same applied to the variable eosinophilic infiltrate. In addition, inflammatory infiltration was more severe in category III, however, statistically, there was no difference between the proposed categories.

Evaluation of three variables into each category, was observed the influence between the variables in categories I and II. However, inflammatory infiltration is the most important variable for having a higher mean score, whereas in category III only biliary duct proliferation and eosinophilic infiltrate were not significant by statistical analysis. 
Therefore, a test of correlation was established between the biliary duct proliferation and inflammatory infiltrate, so finding a moderate association between these variables $\left(r_{s}=\mathbf{0 , 5 5 0 8 ;} P\right.$ $<0,0001$ ). Thus, an increase in the intensity of inflammation occurs biliary duct proliferation moderately.

Considering the great importance of fibrotic lesions in fascioliasis in cattle attempt was made to study their behavior within each category of chronic injury. In the right lobe of the periportal fibrosis is evident in the samples considered as category III for the other categories. With respect to periductal fibrosis, the scores are independent of the category in which the samples were evaluated inserted. However, in many samples there was the presence of ducts or medium-caliber, in which fibrosis were evaluated. This explains the low average score and also its independence from the categories. The diffuse fibrosis of the right lobe proved to be very important, being more severe in samples belonging to category III. When evaluated these fibrotic changes within each category of chronic injury there was no difference in scores in categories I and II, while in Class III, periductal fibrosis and diffuse fibrosis did not differ. However, within all categories, periportal fibrosis was the most important variable in relation to periductal fibrosis and diffuse fibrosis.

Periportal fibrosis in the left lobe proved to be important in category III compared to other categories. The presence of periductal fibrosis was different in all categories, however, was more severe in category III. Regarding diffuse fibrosis, statistical analysis showed no difference for this variable between the categories of injury chronic fascioliasis, however, was more severe in those included in category III. When the variables studied periportal fibrosis, periductal fibrosis and diffuse fibrosis within each category of the left lobe, only periportal fibrosis was important in class $\mathrm{I}$, in other words, chronic injuries in recent periportal fibrosis is the main change observed in fibrotic livers fasciolosis.

\section{DISCUSSION}

Presence of the adult parasite in the biliary ducts was observed, with thickening of duct walls and proliferation and calcification in all samples, revealing a chronic infection according to RietCorrêa et al. (2001). Boray (1969) reports that factors such as parasite load, stage of development of the parasite, type and host age, location and condition of pastures and season influence the variability of pathogenicity and symptoms caused by infection with Fasciola hepatica. However, as the samples were from a slaughterhouse and derived from cattle of different ages, both sexes, varied weight and from different localities in the South of Espírito Santo, variables described above were not used to conduct this experiment because were based on the morphological changes of the injured tissue in naturally infected animals, which is different from experimental infections.

The most prevailing alteration in chronic fasciolosis is the hyperplasia of the biliary ducts in the portal space according to Sadjjadi et al. (1997).

Kishida et al. (2013) found papillary and glandular hyperplasia of the biliary epithelium in liver obtained from meat inspection in Japan and found moderate biliary epithelial hyperplasia in 33,33\% samples following by $66,66 \%$ severe. However, Bostelmann et al. (2000) evaluated bovine liver samples condemned of fasciolosis from a slaughterhouse in Parana State, Brazil, and found a moderate hyperplasia of the biliary ducts in all the evaluated samples. Marcos et al. (2007) in their studies also found a moderate intensity 
Fasciola hepatica

of ductal hyplerplasia. As the aim of this study was the proposal of the classification of chronic injuries, the biliary ducts proliferation was quantified in each portal space, not being considered an intensity parameter of ductal proliferation.In this study, the observation of bile duct proliferation supports the chronicity of infection in samples used in accordance with the literature search. However, is reported only the intensity of this lesion in the liver of infected animals, not taking into account the amount of bile duct. Thus, determining the amount of ductular proliferation assists in determining the time of infection and becomes important in the histopathological evaluations.

Infiltration of inflammatory cells such eosinophiles and lymphocytes was observed by Kishid et al. (2013) in liver of bovine obtained from meat inspection centres in Yamagata and Iwate Prefectures, Japan. Bostelmann et al. (2000) evaluated the inflammatory infiltration in bovine livers infected by Fasciola hepatica and found lymphocytes, plasmocytes, eosinophils, and mastocytes distributed in the medial third of the most calibre ductal wall, besides lymphoplasmacytic and neutrophilic infiltration in the outer third of ductal wall. The lymphoplasmacytic infiltration was moderate. In our study, the discrete infiltration prevailed. As referred by Marcos et al. (2007), the highest frequency found was moderate infiltration. The intensities are attributed by the observers, what explains the differences between the literature and our results. However, it is observed that chronic fasciolosis in cattle in the inflammatory infiltrate is variable and dependent on the host response.

According to Ross et al. (1966), the prevalence of cells as lymphocytes and plasmocytes with lower number of neutrophils and eosinophils at the portal space characterizes a 7 to 11 -week post-infection period. Molina and Skerratt (2005) found periportal lymphocytic infiltration by Fasciola gigantic on the $7^{\text {th }}$ week post-infection, described as discrete infiltration. However, from $12^{\text {th }}$ to $16^{\text {th }}$ week, the inflammatory infiltration was described as severe - characterized by lymphocytes, macrophages and plasmatic cells. The presence, the intensity and the characterization of inflammatory cells contribute to the classification process, as far as it can indicate the schedule of infection by the parasite.

There are a variety of cell types involved in the response by the host independent counsel in the intensity of inflammation observed in the liver parenchyma and the chronic infection decreases the cellular heterogeneity, watching as many mononuclear cells, mainly lymphocytes and plasma cells.

Regarding the eosinophilic infiltration, Bostelmann et al. (2000) also found discrete infiltration of eosinophils in bovine livers with Fasciola sp. and Marcos et al. (2007) related moderate eosinophilic infiltration in theirs samples. Kishida et al. (2013) reveled moderate (50\% samples) and severe $(50 \%$ samples) eosinophilic infiltration in liver of catle obtained from meat center in Japan. The fasciolosis is a parasitic infection and therefore it is natural to find infiltration of eosinophils in the liver parenchyma, but it was observed that chronic infection shows infiltration discreet, perhaps because of the parasites to meet the bile ducts and not in the liver parenchyma as observed in early infection, where migration and the consequent release of products of excretion/secretion of which act as activators of host immune response.

In relation to fibrotic lesions, is noted that the more severe the chronic injury, the greater the amount of connective tissue deposited in the space 
port, supporting thus the assumption that the more severe the injury, the greater the periportal fibrosis. In the study of Marcos et al. (2007) after application of the staging of liver fibrosis throughout the parenchyma, the authors concluded that the worsening distribution of injury causes a severe fibrosis of the liver parenchyma, which was also observed in this study. Was found that the number of layers of connective tissue deposited in the space port increases as the degree of chronic injury. This was observed both in the left lobe and the right. Importantly, the analysis for this variable occurred only in the ducts of medium and large caliber when present in the samples.

From the results, it was observed that only the diffuse fibrosis and periductal fibrosis were shown to be different, in other words, in the ducts of medium and large caliber of the right lobe of the amount of connective tissue layers deposited is smaller than in the ducts present in the left lobe. However, the low average obtained in the evaluation of periductal fibrosis of the right lobe can be under the influence of the absence of ducts in the samples. Phiri et al. (2006) reported the relationship between calcification and Fasciola infection in cattle and fibrosis, fibrotic lesions were found around major bile ducts.

Regarding diffuse fibrosis, left lobe is affected more severely with the deposition of connective tissue often making connections between portal spaces, denoting cirrhotic livers. Marcos et al. (2007) found 16 out of 24 cirrhotic livers examined anatomical pathology. Still, there is a relationship between the reported association of cirrhosis and the number of parasites, when there were more than 40 copies. To Marcos and Terashima (2007) the number of parasites seems to be an aggravation of liver damage and consequently of hepatic fibrosis. In this study, the parasite count was not performed because it samples from slaughterhouses in flux, it is not possible to count or even the collection of specimens, however, we observed the evolution of the fibrotic lesion with the worsening of the injury chronic.

According to Friedman (2000) for the occurrence of liver fibrosis should be railing for months or years. Still, the formation of significant fibrosis is reversible while the cirrhotic state (the last stage of fibrosis as a consequence) is generally irreversible, but for the liver to initiate the fibrotic process should be quantitative and qualitative changes in the composition of the extracellular matrix. Still, there is increased 3-5 times the total content of collagens and noncollagen components and a change in the type of extracellular matrix in the sub endothelial space for forming a matrix containing collagen fibers. The changes that occur in the composition of collagen around the bile ducts are similar to those produced in the liver cirrhosis or other pathological conditions. For Golbar et al. (2013), in fibrotic liver lesions by Fasciola infection in cattle, there are macrophages, myofibroblasts and eosinophiles, and macrophages are associated with liver fluke infection in development of myofibroblast and deposition of extracellular matrices.

Until the present time, no chronic injury classification proposal has been presented correlating inflammatory and fibrotic lesions. However, Marcos et al. (2007) suggest in their study, only the classification of fibrotic lesions with degree I, II and III.

It is important to emphasize that the classification of the variations are related to the level of liver damage due to the fasciolosis. Therefore, in recent infection, many decisive variants to the classification may not be present, oppositely to chronic infections which may lead to a major injury to the liver. Moreover, it is important to be aware of 
re-infections subjected to animals, which may change the injury schedule previously found.

As mentioned, the observation variable is a major contributor in the discrepancy between results on the microscopic evaluation. This is because in each evaluation are established parameters that better define the image analyzed. Thus, differences between results can happen and so natural, however, based on scientific knowledge.

In this study, considered moderate and severe lesions were observed more frequently in the left hepatic lobe. This lobe is the possible entrance of the parasites and because it is anatomically closer to the small intestine. In addition, the largest portion of the bile ducts is arranged in this region of the liver.

The evaluation of each variable between the categories proposed allows studying their behaviour with the worsening of the infection, that is expected in chronic lesions and in different stages there is greater involvement of these variables facilitating the differentiation of the category and its influential role in the implementation classification.

However, as mentioned, only the main lesions observed on histopathologic evaluation were used to study the influence of these variables in the categorization of chronic injuries. Furthermore, the findings of the importance of lesions into the category to which belongs assists the establishment of its importance, and thus establish the influence exerted on each lesion on the other in its category.

\section{CONCLUSION}

The morphologic alterations suggested for the classification were important and adequate to classify the evaluated samples. The proposal of the histopathological classification of hepatic lesions in naturally infected bovine by chronic fasciolosis showed to be a valuable methodology of microscopic evaluation since it allows the establishment of the evolutionary schedule of the illness.

\section{ACKNOWLEDGMENT}

To Fundação de Apoio à Pesquisa do Estado do Espírito Santo, Brazil (FAPES - Research Support Foundation of the Espírito Santo State) for the financial support of the study.

\section{REFERENCES}

BORAY, J. C. Experimental fascioliasis in Australia. Advances in Parasitology, 1969.

BOSTELMANN, S. C. W. et al. Histopatologia comparativa em fígados de bovinos, bubalinos e ovinos infectados por Fasciola hepatica.

Archives of Veterinary Science, v.5, n.1, p.95100, 2000.

FRIEDMAN, S. L. Molecular regulation of hepatic fibrosis, an integrated celular response to tissue injury. Journal of Biological

Chemistry, v.275, n.4, p.2247-2250, 2000.

GOLBAR, et al. Immunohistochemical Characterization of Macrophages and Myofibroblasts in Fibrotic Liver Lesions Due to Fasciola Infection in Cattle. The Journal of Veterinary Medical Science, v.75, n.7, p.857865, 2013.

KISHIDA, K. et al. Investigation of the roles of fascioliasis and food allergy in intrahepatic eosinophilic proliferative pylephlebitis in Japanese Black cattle. The Veterinary Journal, v.196, p.160-166, 2013.

MARCOS, L. A.; TERASHIMA, A. Update on human fascioliasis in Peru: diagnosis, treatment and clinical classification proposal. Neotropical Helminthology, v.1, n.2, p.85-103, 2007.

MARCOS, L. A. et al. Hepatic fibrosis and Fasciola hepatica infection in cattle. Journal of Helminthology, v.81, n.4, p.381-386, 2007.

MOLINA, E. C.; SKERRATT, L. F. Cellular and humoral responses in liver of cattle and buffaloes infected with a single dose of Fasciola gigantica. Veterinary Parasitology, v.131, n.12, p.157-163, 2005. 
PHIRI, A. M. et al. Comparative fluke burden and pathology in condemned and noncondemned cattle livers from selected abattoirs in Zambia. Onderstepoort Journal of Veterinary Research, v.73, n.4, p.275-281, 2006.

RIET-CORREA, F.; SCHILD, A. L.; MÉNDEZ, M. C.; LEMOS, R. A. A. Doenças de Ruminantes e Eqüinos, São Paulo: Varela, $2^{\text {th }}$ Ed., 2001. $998 \mathrm{p}$.

ROSS, J. C.; TODD, J. R.; DOW, C. Single experimental infections of calves with the liver fluke, Fasciola hepatica (Linnaeus, 1758). Journal of Comparative Pathology, v.76, n.1, p. $67-81,1966$.

SADJJADI, S.M.; TAKI, T.M.; ORYAN, A. Quantitative histopathology of liver and portal lymphnode in chronic bovine fascioliasis. Indian Journal of Animal Sciences, v.67, n.4, p.270274, 1997.

WORLD HEALTH ORGANIZATION - WHO. Study group on the control of foodborne trematode infections. Control of foodborne trematode infections: report of a WHO study group. Report Technical Series, Geneva, 1995. Disponível em:

<http://whqlibdoc.who.int/trs/WHO_TRS_849_(p art1).pdf>.Acesso em: Maio, 2009. 